\title{
9. INSTRUMENTS AND TECHNIQUES (INSTRUMENTS ET TECHNIQUES)
}

PRESIDENT: V. B. Nikonov.

Vice-President: A. B. Meinel.

Organizing Committee: W. A. Baum, W. C. Livingston, J. D. McGee, N. N. Mihelson, J. Ring, B. Valniček.

\section{INTRODUCTION}

There are four Working Groups of Commission 9: 'Photo-Electric Image Devices', 'Large Telescopes', 'Data Systems' and a Joint Working Group of Commissions 9 and 46 'Exchange of Equipment'.

The first of these groups - 'Photo-Electric Image Devices' (Chairman Dr G. Wlérick) - was very active. The Report of its Chairman is published below. The Working Groups 'Large Telescopes' and 'Data Systems', created at Brighton, have not yet started their work. The possible reason is the great activity of Commission's members at Symposia and Conferences on astronomical techniques, held in Edinburgh, Geneva, London and Lick Observatory during 1970-1972. These very representative Symposia and Conferences provided opportunities for all the necessary contacts and discussions. At the Sydney Meeting of the Commission the future of these Working Groups should be reconsidered.

The Joint Working Group 'Exchange of Equipment' (Chairman Dr N. N. Mihelson) cleared up the question of the possibilities of such exchanges. All the answers received up to the present from several observatories were negative.

\section{A BRIEF OUTLINE OF PROGRESS IN ASTRONOMICAL TECHNIQUES DURING 1970-1972}

The last years have been characterized by extensive developments in astrophysical research. New types of astronomical objects and processes have been discovered. Quasars, $N$ and Radio Galaxies, $X$-Sources and Pulsars may be mentioned. Instability of Seyfert Galaxies and the ultra short variability of pulsars are examples of unstable processes occurring in astronomical objects. Careful investigation of such processes is of fundamental value for understanding the as yet unknown properties of matter and the physical nature of processes occurring in the Universe. But all such astronomical objects are in general extremely faint and the most powerful and perfect astronomical instrumentation is needed - in particular large telescopes. In the early sixties only three telescopes larger than $2.5 \mathrm{~m}$ were in operation. At that time it was clearly understood that for the further progress of astrophysics many very large telescopes were badly needed. And in different countries projects for the construction of 3.5-6 $\mathrm{m}$ telescopes have been started.

Work on the design and construction of these telescopes showed fair progress during the last three years. The $6 \mathrm{~m}$ altazimuth telescope of the Special Astrophysical Observatory (U.S.S.R.) has been mounted. The electronics is being adjusted and the final figuring of the large mirror is in progress (Kopylov, 05.032.040). The $4 \mathrm{~m}$ telescope of the Kitt Peak National Observatory (U.S.A.) is being put into operation. The $4 \mathrm{~m}$ telescope of the Cerro Tololo Interamerican Observatory (Chile) is expected to be ready for operation at the end of 1973 . The $3.66 \mathrm{~m}$ telescope of the European Southern Observatory (Chile) is under construction. Work on other large telescopes is continuing. These are: two $3.6 \mathrm{~m}$ telescopes, the Canadian and Anglo-Australian, and two $3.5 \mathrm{~m}$ telescopes one for the Max Planck Institute for Astronomy (F.R.G.) and the other for the National Institute 
of Astronomy and Geophysics (France). The great success in the building of large telescopes is evident. In the near future the possibilities of studying the faintest astronomical objects will be enormously enlarged.

It must be noted that most of the telescopes mentioned above are of the Rithey-Chrétien type. It is well known that this type of telescope, having a cassegrain focal ratio $F / 8-F / 9$, is by far the best for observations of the fainter stars and galaxies. However, construction of these large RitheyChrétien telescopes only became possible when special control methods for testing large aspherical mirrors have been developed.

Many innovations in telescope design have been recently introduced. Step and torque motors for telescope driving and TV dissectors for automated guiding may be mentioned in this connection. To obtain the greatest economy in telescope time all large telescopes are supplied by automation systems based on computer techniques.

In spite of progress in large telescope construction of telescopes up to $6 \mathrm{~m}$, the need for much larger giant telescopes still exists, especially for infrared observations. Construction of such telescopes according to the present types of design, would be extremely difficult and expensive. To overcome these difficulties principally new types of designs were proposed. One of them is the 'Multi Mirror Telescope' - a joint project of the Smithonian Observatory and the University of Arizona. This is a combination of six mirrors on one mounting having a common field of view. The first telescope to be constructed will be equivalent to a $4.4 \mathrm{~m}$ one (Meinel and Shannon, Opt. Eng., 1972, 11, 33; Weymann and Carlton, Sky Telesc., 1972, 44, 159). Another project is the 'Telescope Array' of the Dominion Observatory, Victoria. It consists of twenty-five $1.9 \mathrm{~m}$ telescopes also with a common field of view and equivalent to a telescope of $7.6 \mathrm{~m}$ (Richardson, Odgers, J. Roy. Astr. Soc. Canada, $1972,66,99)$. The French 'Télescope composée' project should also be mentioned. Work on some of these projects has just started.

It is evident that the possibilities of a telescope are determined not only by its light gathering power but also by the auxiliary instrumentation used. The progress attained in this respect during the last three years is very significant.

In the first place the development of various types of image tubes, electron cameras and TV systems should be noted. The application of modern image tubes, sometimes in combination with TV systems, leads to a considerable shortening of exposures resulting in a remarkable economy of telescope time and providing the possibility of studying very fast processes of different kinds (spectroscopy of flare stars, for example). Various new types of spectrophotometers and scanners have been developed (Morton, ESO Conf., 1972, 317); digitalisation of their output data has also been achieved (Wood, ESO Conf., 1972, 165). For optical identification of pulsars a TV 'Pulsar hunter' has been constructed (Abramenko and Prokof'eva, 04.141.206; Astron. Zirk., 1962, 708, 6). Electron photography, when applied to the study of fine structure and the photometry of distant galaxies and the faintest stars, gave results unobtainable by common photography. This is a consequence of the linearity of electronographic characteristic curves and the high quantum efficiency of electron cameras. One can expect to reach $27^{\mathrm{m}}$ stars with a 4-6 m telescope when the seeing is very good (Wlérick, ESO Conf., 1972, 399). It must be noted also that the accuracy of electronographic photometry was found to be comparable with that of photoelectric photometry. The very high resolution of electronographs on using fine grain nuclear emulsions (like L4) stimulates the revision of optical parameters of astronomical spectrographs.

The progress of common photography, always used when observing large stellar fields, was remarkable. The new types of Kodak emulsions IIIaJ and IIIaF are much more sensitive than the best ones used up to the present.

Great progress may be observed in the development of photomultipliers. A very interesting type of photocathode (III-V) has been created (Spicer and Bell, P.A.S.P., 1972, 84, 110). It has a very high quantum efficiency and its spectral responce curve is flat from $9500 \AA$ to $1000 \AA$. Experimental photomultipliers using this type of photocathode have been manufactured by RCA (see below the report of Dr R. G. Tull). The well known channeltrons were successfully applied in scanners (Wood, ESO Conf., 1972, 165). Multi-anode photomultipliers based on the utilization of multi- 
channel electron multipliers have been developed (Cathpole and Johnson, Publ. A.S.P., 1972, 84, 134). They will be very useful in colorimetry and spectrophotometry of low resolution.

Stellar photoelectric magnetographs of high sensitivity have been constructed and put into operation (Severny, 03.116.003).

Bowen's image slicers obtain a new life when applied to photoelectric spectrophotometry of high resolution (Richardson, ESO Conf., 1972, 275). Holographic gratings have now been successfully used in astronomical spectrographs (Labeyrie et al., ESO Conf., 1972, 203; Schmahl and Rudolph, ESO Conf., 1972, 209). Echelle spectrographs and scanners (Schroeder, Publ. A.S.P., 1970, $82,1253)$, and also interference methods, are being widely applied in astronomical spectroscopy. The Fourier transformation method, when applied to large scale photographs taken with a $5 \mathrm{~m}$ telescope, enable one to reach the resolving power of this telescope limited by diffraction. Some spectral binaries have been resolved and the angular diameter of Betelgeuse has been measured (Brook et al., Sky Telesc., 1971, 42, 11).

Concluding these brief remarks, considerable progress was made in astronomical techniques during 1970-1972. It should also be mentioned that many recent developments in astronomical techniques (control methods for aspherical mirrors, holographic gratings, electron photography, methods of very high speed observations, etc.) are of great value, not only for astronomy but also for modern phys, cs, applied optics and other technical sciences.

\section{CONFERENCES AND SYMPOSIA}

Five very important Conferences and Symposia were held during the period reported: Colloquium 11 of the IAU 'Automation in Optical Astronomy', Edinburgh, August 1970 (Publ. Obs. Edin., 1971, 8): two Conferences supported by ESO and CERN 'Large Telescopes Design', Geneva, May 1971 and 'Instrumentation of Large Telescopes', Geneva, June 1972; Symposium 'Advanced Electronic Systems in Astronomy', Lick Observatory, August-September 1971 (Publ. A.S.P, 1972, 84); 'The Fifth Symposium on Photo-Electronic Image Devices', Imperial College, London, September 1971 (Adv. Electron. Electron Phys., 1972, 33 A,B, Academic Press, London).

All these Symposia and Conferences were of utmost importance in presenting the latest achievements in the field of astronomical techniques.

\section{REPORTS}

Many recent results achieved in the development of astronomical techniques may be found in the reports kindly sent, as usual, by Commission members and representatives of Astronomical Institutions. These reports will be found in the following text. Most of the reports are published without abbreviations, though a few of them are summarized and some were used for compilation. Only problems concerning ground-based astronomical techniques were included in the reports. All materials concerning balloon, rocket, and satellite observational techniques have been omitted and passed to the President of Commission 44, Prof. V. K. Prokof'ev.

The President of this Commission is very grateful to all who kindly sent him the necessary materials, and to Dr N. N. Mihelson, member of the Organizing Committee, for his help in the preparation of the present report.

All reports are presented in alphabetical order of the names of the contributers.

\section{Ch. M. Anderson (Washburn Observatory)}

Recent instrumentation work at the Washburn Observatory has concentrated on the application of echelle spectrometers to astronomical measurements. A Cassegrain echelle spectrometer has been constructed and has been in use for approximately three years (Schroeder and Anderson, 06.034.085), in conjunction with the 91-cm reflector at the Pine Bluff Observing Station. The instrument is utilized in two different modes. For the measurement of emission line ratios in gaseous nebulae, it is operated as a simple monochromator with pulse counting photomultiplier read-out. Crucial to 
implementation of this application has been the solution of the problem precise wavelength location in the complex two-dimensional focal plane pattern of an echelle spectrometer. Anderson and Bohuski (1973, in preparation) discuss the method by which polynomial fitting formulae have been established for the computer controlled location of any particular wavelength to within $\pm 0 \cdot 1 \AA$. The computer system which controls the instrument has been discussed by McNall et al. (1972, Publ. A.S.P., 84, 176). For use in stellar line profile work, the concept of utilizing the phosphors of an image intensifier stack as a temporary storage medium has been developed by McNall et al. $(1972$, Publ. A.S.P., 84, 145). In this system the output of an ITT F 4724 intensifier is scanned under the control of the PDP-8 computer by an ITT F4011 image dissector. Early results indicate that a speed increase on the order of 100 can be realized with photometric accuracy.

A new system has recently been installed on the Pine Bluff Observatory $41 \mathrm{~cm}$ reflector for computer-controlled low resolution photoelectric spectrophotometry. The PDP-8/L computer programs developed by Schiffer increase the efficiency with which this type of observation can be made. Thus in the visual and near ultraviolet at a band pass of $40 \AA$ observations to better than $1 \%$ count statistics can be obtained for all the standard wavelengths of Oke or Hayes on a $V=10.0$ star in about 20 min. Fully remote and automatic operation of this instrument is presently being studied.

\section{R. d'E. Atkinson (Goethe Link Observatory)}

The Goethe Link Observatory's $91 \mathrm{~cm}$ Newtonian telescope has been converted to an $F / 10$ Cassegrain with modern mount, drive, and readout. The telescope is equipped for direct photography, spectroscopy, wide and narrow band photoelectric photometry, and spectral scanning. A single stage ITT image tube with S-20 photocathode is available.

A rapid spectral scanner is in operation, built around a 1024-channel signal averagar with readout to magnetic tape (Honeycutt, 05.34.070). The single channel spectrometer can be programmed to scan continuously over pre-selected wavelength ranges at any of several speeds up to $2500 \AA \mathrm{s}^{-1}$, or to step repeatedly between a number of pre-selected wavelengths, pausing at each wavelength for a timed integration. S-20 and S-1 photomultipliers permit observation from 3300-11000 $\AA$ at $20 \AA$ resolution. Some preliminary results have been published (Honeycutt, 1972, Astron. J., 77, 24; Fay and Honeycutt, 1972, Astron. J., 77, 29).

Another data acquisition system was installed at the $41 \mathrm{~cm}$ telescope, built around a 4906-channel signal averager with readout to magnetic tape. This system has been used extensively as an area scanner for extended objects by signal averaging drift scans until the desired $S / N$ is reached. Having the $U, B, V$ drift scane stored on magnetic tape permits use of a large computer to produce contour maps of surface brightness or color from the $10^{4}-10^{5}$ data points (Burkhead and Honeycutt, 1972 Astron. J., 77, 24). A second application has been Burkhead's $U, B, V$ stellar photometer which operates in conjunction with the averager. The filter wheels is spun continuously and two different size diaphragms are substituted on alternate cycles to measure sky. Again one simply accumulates data, displayed on the real-time oscilloscope, until the desired $S / N$ is attained.

Both averagers have been modified to permit their use in observing lunar occulations of stars at millisecond time resolution (Warren, 1971, Thesis, unpubl.).

During 1972 Honeycutt completed an infra-red detector system for use on the rapid scanner, consisting of a dry-ice cooled $\mathrm{PbS}$ cell, focal plane chopper, and lock-in amplifier.

Burkhead and Honeycutt have recently modified the Meinel Cassegrain spectrograph to accept an SSR Instrument silicon diode television camera system with 500 channels of simultaneous detection. A new camera was constructed for the spectrograph and a dry-ice cooled cold box of novel design was built for the television camera tube. This system is undergoing laboratory and telescope testing during the fall of 1972.

\section{G. Bakos (Department of Physics, University of Waterloo, Canada)}

Among the new instrumentation at the University of Waterloo Observatory the following should 
be mentioned: A digitized $X-Y$ comparator by Mann, a digitized Cuffey astrophotometer by Astromechanics and a modified Hilger-Watt microphotometer equipped with a curve follower.

\section{A. Baranne (Observatoire de Marseille)}

Baranne, Duchesne procèdent aux essais à l'Observatoire de Haute Provence de deux spectrographes selon le montage à pupille blanche, (miroir collecteur) (ESO Conf., 1972, 241).

Le premier spectrographe, 'Echelec 152', est un spectrographe coudé à dispersion croisée.

Le deuxième est un spectrographe Cassegrain destiné à l'infrarouge proche (Colloque de Liège, Les nèbuleuses planétaires, Juin, 1972).

Ces deux spectrographes peuvent indifférement etre utilisés avec plaques photographiques, tubes image et caméra électronique.

Suivant la méthode préconisée par Griffin à Cambridge, Baranne, en collaboration avec Mayor, et Poncet de l'Observatoire de Genève, construisent un prototype de spectromètre Cassegrain utilisant un réseau échelle pour la détermination photoélectrique des vitesse radiales.

\section{W. A. Baum (Lowell Observatory)}

Among the present instrumentation projects at the Lowell Observatory, three involve new or experimental technology. In one of these projects photoelectric scanners are combined with PDP-11 computers so as to form integrated data systems. An area-scanning spectrometer was used in this manner by Boyce to observe selected regions on Mars during the 1971 apparition. A second system has recently been used by Slettebak, White and Boyce to record the accurate profiles of spectrum lines from which, for example, stellar rotation rates can be derived. Data reductions are aided by the use of an 'interactive graphics' display of data operations on an oscilloscope.

Another development procject concerns the stabilization of planetary images by an electronic device for image tremor compensation. The present design uses a servo-driven optical element together with magnetic deflection coils surrounding an image converter to make fast corrections for image motion. Stabilized planetary images recorded by Baum, Busby, and Pettauer are slightly better than unstabilized images when the 'seeing' is poor. The results indicate that such devices may have more value for automatic guiding than for image sharpening.

A third developmental project is the design by Baum and Busby of an optical instrument for rectifying a large number of planetary images. Selected photographs from the International Planetary Patrol collection will thereby be converted to sets of images as seen from standard viewing angles. These should help to provide, for example, better insight concerning cloud flow patterns on Jupiter.

\section{J. Bhattacharrya (Indian Institute of Astrophysics)}

A solar magnetograph using an electro-optical light modulator and a $\lambda / 4$ plate was put into operation in Kodaikanal Observatory. The equipment has facilities for simultaneous measurement of longitudinal magnetic field and line of sight velocities. A precision image scanner unit for use with the horizontal solar telescope is under fabrication. Attempts to incorporate a modification to allow simultaneous multichannel scanning and obtaining data in digital form are in progress. (Kodaikanal Obs. Bull., 1972, No. 205)

Electronic instrumentation for pulse counting technique in faint star photometry has been completed and put in field trials. Observations on some faint Cepheid variables and the Sco-X-I source has shown encouraging signs of capability of the new system.

A fast response photometer recording system was rigged up and used for three occultation observations e.g., $\beta$-Sco by Jupiter on 13.5.71, SAO 186800 by Ganymede on 7.6.1972 and SAO 186658 by Ganymede on 19.6.1972.

An infrared stellar photometer using Kodak ektron E-6 detector is under construction in our laboratories. It is proposed to use the same from ground-based telescopes in Kodaikanal and Kavalur. 
A photometer with electro-optical polarisation modulator is under construction; the equipment is intended for studies of total circular polarisation from white dwarfs to detect strong magnetic fields.

In our optical shop which has grown considerably during past few years, the facilities for generating optical surfaces up to $100 \mathrm{~cm}$ and of vacuum deposition of aluminium on surfaces up to $66 \mathrm{~cm}$ have been developed. A number of optical surfaces for telescopes, spectrograph collimators, Schmidt and Maksutov cameras have been made and are under preparation.

\section{N. Boneff (Report for Bulgaria)}

The following apparatus has been constructed in Bulgaria at the Astronomical Section of the Bulgarian Academy of sciences:

A Mirror Telescope; $500 \mathrm{~mm}$; primary $F / 5$; Cassegrain $F / 15$; fork mounting; complete with a photoguide for remote control. Its assembling envisaged (Blazhev and Pamukchiev).

A Dome (diameter $5 \mathrm{~m}$ ) of plastic; heat insulated; titanic coating; sunchronized with the telescope (Blazhev and Petrov).

At the People's Observatory of Stara Zagora:

A Visual photometer designed to investigate changes of light intensity reflected by artificial satellites. Accuracy of time registering, $0 \mathrm{~m} 1$.

Photoelectric Photometer designed to investigate light intensity of the night sky $(D=80 \mathrm{~mm}$; $F=300 \mathrm{~mm}$ ) using interference filters of half-width equal to $50 \AA$. Photocurrent of the photomultiplier is registered by a potentiometer. The photometer is installed on an azimuthal platform allowing scanning of the sky.

An Automatic Photoelectric Photometer $(D=130 \mathrm{~mm} ; F=600 \mathrm{~mm}$ ) with four filters. This is designed to investigate light emission of the surrounding space.

\section{G. Courtés (Laboratoire d'Astronomie Spatiale Marseille)}

Un nouveau reducteur focal (transformant le rapport $F / 5$ en rapport $F / 1$ et $F / 0.7$ ) a été construit et utilisé sur plusieurs télescopes, dont, en particulier, le telescope de $5 \mathrm{~m}$ du Mont Palomar grâce a un correcteur $F / 3.3-F / 5$ construit par Baranne. Cet instrument a permis a Courtès, Cruvellier, Deharveng, Monnet et Pellet d'obtenir de nombreux résultats sur les vitesses radiales (méthodes interférentielles) de l'hydrogene en émission des galaxies du groups local $(01.158 .004 ; 03.159 .004$; 03.132.013;04.158.067).

Un appareil à grand champ $\left(55^{\circ}\right)$ à grand rapport d'ouverture $F / 0.7$ utilisant, grâce à un transfert d'image, des filters interférentiels très sélectifs (quelques Ångströms) a été construit et a permis a Courtés et Sivan de mettre en évidence de nouvelles régions $\mathbf{H}$ in et de faire un atlas complet de l'émission galactique. (Astrophys. J. Letters, 1972, 11, 159)

Deux spectrographes Cassegrain nébulaires (dispersion $=50 \AA \mathrm{mm}^{-1}$ ) du type Baranne (Litrow + +réducteur focal catadioptrique) ont été conçus et mis au point par Mme Ulrich-Demoulin, Deharven et Pellet. Ces deux derniers ont, de plus, recherché les meilleures solutions de couplage avec tube image ITT et RCA (04.034.045).

Un spectrographe stellaire et nébulaire sans rotation de champ et équipé de tube image a été conçu par Georgelin pour le foyer coudé des telescopes de $150 \mathrm{~cm}$. La mécanique a été réalise a l'observatoire de Haute Province.

Des essais très prometteurs ont été faits par Courtès (Compt. Rend. Ser. B, 19, 264, 1757). Monnet (04.031.037) et Georgelin à l'aide de trames de lentilles en vue du traitement photométrique direct d'images télescopiques.

La reconstitution d'images a été particulièrement réussie par Vulmière à l'Institut d'Optique de Paris.

Un spectromètre interférential Fabry Perot a été conçu et réalisé par Cruvellier et utilisé par Cruvellier et Caplan pour l'étude du doublet 3727 de O II (Astron. Astrophys., 1972, 18, 480). 
Un grand sidérostat polaire de $1 \mathrm{~m}$ de diamètre utile, de rapport d'ouverture $F / 5$ a été installé au Laboratoire d'Astronomie Spatiale du C.N.R.S. à Marseille. Il a été utilisé à la spectrométrie Fabry Perot par Caplan et à l'interférométrie à deux ondes par Cagnet de l'Institut d'Optique de Paris.

\section{A. W. J. Cousins (Report for South Africa)}

\section{South Africa Astronomical Observatory}

The former Republic Observatory, Johannesburg and Royal Observatory, Cape of Good Hope have been combined with the title South Africa Astronomical Observatory, and a new outstation has been established near Sutherland on the Karroo. The $51 \mathrm{~cm}$ Boller and Chivens reflector from Johannesburg and the $1 \mathrm{~m}$ Grubb-Parsons reflector and Tayler, Tayler and Hobson astrographs from Cape Town are now at the Sutherland site.

New auxiliary equipment includes a two-channel photometer, an infrared (1.25-20 $\mu$ ) photometer, several solid state DC amplifiers, a D-Mac plotting machine (to obtain approximate star coordinates from photographic plates as a preliminary to measurement with a Galaxy machine) and a computer-controlled Joyce-Loebl measuring machine (for use with electronographic plates). It is anticipated that we will have a McMullan image tube in operation on the $1 \mathrm{~m}$ reflector before the end of 1972.

A grating spectrograph with dispersions of 40 and $80 \AA \mathrm{mm}^{-1}$ is being borrowed from the Royal Greenwich Observatory for use on the $1 \mathrm{~m}$ reflector.

\section{Department of Astronomy, University of Cape Town}

Warner and Nather (Univresity of Texas) have developed a sophisticated photometer coupled to an on-line computer, more especially for high-speed photometry (e.g. of lunar occultations flare stars and dwarf novae). It can also be used for time-shared multicolour photometry, polarimetry and the scanning of double star images. It will be used at the Sutherland outstation.

\section{Boyden Observatory, Bloemfontein}

Jarrets reports that the $152 \mathrm{~cm}$ reflector has been fitted with new Cassegrain optics and that the old Gerrish drive has been replaced by a new electronic drive. A new Universal Jena grating spectrograph has been acquired, giving dispersions from $280 \AA \mathrm{mm}^{-1}$.

A pulse counting photometer is under construction.

\section{Radcliffe Observatory Pretoria}

This observatory has acquired a two-channel 'People's' photometer and a new solid state amplifier (both designed at the Royal Greenwich Observatory). The image tube spectrograph is now in regular use.

\section{A. Dalgarno (Harvard College Observatory)}

A completely automatic, sky-compensated, polarimeter-photometer, capable of recording many wavelengths in rapid succession was constructed in the Observatory shop under the supervision of Visvanathan (1972 Publ.A.S.P., 84, 248). A fast digital system, consisting of a Fab-tec computer and magnetic tape recorder, was assembled to record the observations. The instrument provides also for continuous display on an oscilloscope of the observations being obtained during either polarimetry or photometry.

Liller has combined a 3-stage Varo image intensifier tube with a nebular spectrograph $\left(240 \AA \mathrm{mm}^{-1}\right.$ reciprocal dispersion) which is normally used at the $F / 5$ Newtonian focus of the $155 \mathrm{~cm}$ reflector.

A new eclipse spectrograph for study of coronal streamers was constructed, following a design by Baker, and used by Menzel and Pasachoff at the eclipse of 7 March 1970. The instrument has a slit long enough to cover a field of 10 solar radii to either side of the disk, and photographically records the spectrum from 3500 to $6000 \AA$. (04.034.085). 


\section{Delbouille (Report for Belgium)}

A program has been developed at the Belgian Royal Observatory (Brussels) to observe visual double stars with a $45 \mathrm{~cm}$ refractor and the aid of television techniques, using an EBS tube after an image intensifier (Dommanget). Short exposures (1/25 s) are taken and magnetic tape recording makes further careful examination possible. Stars of visual magnitude 10 separated by only $2^{\prime \prime}$ are easily observed, and it seems possible to reach a limit of the order of $0.5^{\prime \prime}$.

The Observatory has designed a new automatic photographic device applying the Metcalf technique to detect moving bodies, now installed on a Zeiss double astrograph, as well as a special variable exposure shutter $(0.008-0.020 \mathrm{~s})$ to take pictures of the Moon on stellar background.

The laboratory of Astrophysics of the University of Mons has established, in collaboration with the University of La Laguna (Tenerife), a small station on Tenerife island (Houziaux). The Belgian university has furnished the actual equipment: a Newton-Cassegrain telescope, diameter $540 \mathrm{~mm}$ $(F / 5$ and $F / 15)$, a photolectric photometer built by the Geneva Observatory, one spectrograph with plane grating, 600 lines $\mathrm{mm}^{-1}$, dispersion $80 \AA \mathrm{mm}^{-1}$ in the second order, and a Kron-type electronographic camera, now under construction.

The Institute of Astrophysics of the University of Liege has developed a new facility to polish and figure high quality large astronomical mirrors, up to $1.8 \mathrm{~m}$. The shear-wave interferometry technique for the tests has been thoroughly developed and extensively used together with other more classical techniques.

\section{Detre (Report for Hungary)}

The Heliophysical Observatory at Debrecen obtained a large coronograph $(D=50 \mathrm{~m}, F / 8)$ from the U.S.S.R., of the same type which is used at the Kislovodsk Station of the Pulkovo Observatory. It will be installed this year.

The Konkoly Observatory ordered a $1 \mathrm{~m}$ Ritchey-Crétien telescope from VEB Zeiss Jena, and this will be installed in 1974. A $10 \mathrm{~m}$ dome is under construction.

The sputnik station at Baja was presented with an AFU camera from the Soviet Union for traking faint artificial satellites.

In the workshop of the Konkoly Observatory several photoelectric photometers and polarimeters are under construction.

\section{H. Elsässer (Max-Planck-Institut für Astronomie)}

The northern hemisphere observatory of the Max-Planck-Institut für Astronomie will be located on the Calar Alto $(2168 \mathrm{~m})$ near Almeria in the south-east of Spain. This site was chosen after extensive seeing investigations in the Mediterranean area. Site development is in progress, after a contract of collaboration was signed by the Spanish and German authorities in 1972. The final decision on the location of the southern hemisphere observatory (Chile or South-West Africa) could not be taken until summer 1972. Seeings measurement at both sites have shown that the Gamsberg (South-West Africa) is at least of the same quality as La Silla (Chile) concerning seeing and number of clear nights $(05.032 .039$; ESO Conf., 1972, 23)

A $1.2 \mathrm{~m}$ Ritchey Chrétien telescope, completed in 1971 by C. Zeiss, Oberkochen (G.F.R.), will be installed in Spain during 1973/74. For this telescope a Boller and Chivens Cassegrain spectrograph with $10 \times 13 \mathrm{~cm}^{2}$ gratings has been delivered in 1972 . Two identical fork-mounted, computer controlled Ritchey Chrétien telescopes are under construction at $C$. Zeiss (05.032.057). The first one destined for the northern observatory, is being assembled in the shop since 1972 . Both $2 \cdot 2-\mathrm{m}$ telescopes are to be equipped with coudé spectrographs, which have been specified; they will use $30 \times 40 \mathrm{~cm}^{2}$ gratings and two cameras of $90 \mathrm{~cm}$, resp. $360 \mathrm{~cm}$ focal length (ESO Conf., 1972, 83). A 3.5-m telescope was ordered from C. Zeiss under a contract signed in 1971 . The optical system provides for a $F / 3.5$ prime focus, including two different correctors, a $F / 10$ Ritchey Chrétien focus, and a coudé focus. The mounting of the telescope will be of the Palomar-horseshoe type. Detailed specifications of the tubes and mounting construction are in progress. 


\section{Ch. Fehrenbach (Observatoire de Haute Provence, St. Michel l'Observatoire)}

Un seul nouvel instrument est à signaler à l'Observatoire de Haute Provence. Il s'agit d'un Télescope de Schmidt ayant un mirroir de $90 \mathrm{~cm}$ et une lame de $60 \mathrm{~cm}$ avec une focale de $2 \cdot 10 \mathrm{~m}$.

Cet instrument est à la fois la propriété de l'Institut d'Astrophysique de Liège et de l'Observatoire de Haute-Provence. Il est devenu opérationnel en juillet 1970. Il a surtout servi à la recherche des Comètes. Il comporte aussi un prisme donnant une dispersion de $400 \AA \mathrm{mm}^{-1}$.

On a aussi mis en service un petit télescope de $40 \mathrm{~cm}$ pour mettre au point la mise en station automatique des instruments ainsi que la photométrie automatique. Cet instrument es opérationnel depuis le début 1972.

\section{N. Gökdogan (Report for Turkey)}

\section{Middle East Technical University}

Starting in Spring 1970 a new programme in Astrophysics and Space Sciences was initiated at the Physics Department. During the following two years new astronomical equipment employing novel techniques was developed and a programme of high resolution interferometric spectroscopy has been started.

A Pepsios as well as a single Febry-Perot spectrometer are currently under construction at METU. These instruments are designed to give a resolution $R(R=\lambda / \Delta \lambda)$ of between $7.5 \times 10^{4}$ and $10^{6}$ in the visible and near infra-red region of the spectrum.

\section{Ankara University Observatory}

A Maksutov telescope for photo-electric observations is about ready for operation. Instruments in use: Coudé telescope for sunspots observations.

Istanbul University Observatory

Application has been made for the purchase of a 1.0-1.2 m telescope. Instruments in use: A $30 \mathrm{~cm}$ Astrograph and a Lyot filter.

Ege University Observatory

Instruments in use: A $48 \mathrm{~cm}$ Cassegrain reflector and $13 \mathrm{~cm}$ spectrograph.

\section{Kandilly State Observatory}

New equipment since 1970: A K-line filter; $\mathrm{H} \alpha, 0.5 \AA$ pass band filter for automated filming. Foreseen for 1972/73: 8 and $15 \mathrm{~m}$ focal length Spectroheliographs; a $\lambda 10830$ filter.

\section{R. L. Hilliard (Steward Observatory)}

\section{Telescopes}

In current operation at our station on Kitt Peak, Steward Observatory has a Boller and Chivens $2.3 \mathrm{~m}$ fork mounted Ritchey-Chrétien telescope (dedicated in 1969), and the Warner and Swasey $0.9 \mathrm{~m}$ fork mounted telescope which was constructed in 1921. Soon to join these will be a Tinsley $0.5 \mathrm{~m}$ telescope with German mount, which was recently donated to the Observatory by the United States Navy. This telescope has an $F / 3.6$ prime focus as well as $F / 14$ and $F / 23.5$ Cassegrain foci. It is planned that this telescope will be used primarily for photoelectric photometry. The Observatory also has an Astro Mechanics $0.5 \mathrm{~m}$ telescope located on the University of Arizona Campus.

\section{Multiple-Mirror Telescope (MMT)}

The Observatory is a member of the working group, including also the Smithsonian Astrophysical Observatory and the Optical Sciences Center of the University of Arizona, which is developing a six-telescope array known as the Multiple Mirror Telescope or MMT and equivalent to one 4.4 meter telescope. (Sky Telesc., 1972, 44, 159.). 
The primary task of the Observatory at present is the development of the optical alignment system to keep the images from the six $1.83 \mathrm{~m}$ telescopes superimposed at the combined focal plane. Briefly, this is accomplished by sensing the position of the beams from an artificial light source which traverse the optical systems in the same manner as starlight, and using the resultant erorr signals to actively align the stellar images by tilting the telescopes' secondaries.

\section{Auxiliary instruments}

The $2.3 \mathrm{~m}$ telescope Boller and Chivens Cassegrain spectrograph has had adapted to it, for some types of observing programs, a prism cross-dispersing element which is used with a $100 \times 100 \mathrm{~mm}$ $180 \mathrm{~g} \mathrm{~mm}^{-1}$ Bausch and Lomb grating blazed at $4.5 \mu$. This results in a relatively low-dispersion (50-100 $\AA \mathrm{mm}^{-1}$ ) low order (6th through 14th) echelle spectrograph giving several thousand angstroms of spectrum on a $16 \times 19 \mathrm{~mm}$ plate in one exposure.

Also being developed for the $2.3 \mathrm{~m}$ telescope is a large Cassegrain Echelle spectrograph intended primarily for use with image intensifiers and television systems. This spectrograph will have three cameras: a $16 \mathrm{~cm}$ focal length Schmidt (for normal photographic detection only), a $40 \mathrm{~cm}$ focal length off-axis folded Schmidt, and a $120 \mathrm{~cm}$ focal length Ritchey-Chrétien. These will give dispersions of $10 \AA \mathrm{mm}^{-1}, 4 \AA \mathrm{mm}^{-1}$ and $1.3 \AA \mathrm{mm}^{-1}$ respectively at $5000 \AA$. Two Bausch and Lomb $128 \mathrm{~mm} \times 254 \mathrm{~mm}$ Echelle gratings will be available: a $31.6 \mathrm{~g} \mathrm{~mm}^{-1}$ and a $79 \mathrm{~g} \mathrm{~mm}^{-1}$. For crossdispersion, Perkin-Elmer $200 \mathrm{~g} \mathrm{~mm}^{-1}$ and $600 \mathrm{~g} \mathrm{~mm}^{-1}$ gratings (special-made masters), as well as $18^{\circ}$ and $46^{\circ}$ prisms will be available to provide a choice of order separation and total spectral coverage. It is expected that this spectrograph will begin operation in late 1973.

There are two magnetically focused image intensifiers in use on the $2.3 \mathrm{~m}$ telescope; a two-stage RCA intensifier, that is used primarily on the Cassegrain spectrograph; and a two-stage ITT intensifier, with a fiber optic output, which is used primarily for direct photography, but which is now being adapted for use also with the spectrograph. Also being developed for use on the spectrograph is a photon-counting television system using a 4-stage EMI intensifier and a SEC television camera.

A television system, developed by Quantex Corp., is being installed on the $2.3 \mathrm{~m}$ telescope for filed acquisition and guiding. Two SEC television cameras, with single stage intensifiers, are avilable. In the case when the spectrograph is in use, for example, one camera will be at the widefiled eyepiece position for field acquisition; the second will view in front of the slit for guiding. The display from either of the cameras can integrate over a period well in excess of that needed to detect dark sky, and within a few seconds 20th magnitude stars can be seen on the display.

\section{Data reduction}

Aided by a grant from the National Science Foundation we have acquired several modern measuring and reduction instruments. These are: a David W. Mann Measuring Engine with Data Logger and card punch, a Grant Micrometer which is now being digitized, a Gaerner M1237 Blink Comparator, and a Boller and Chivens Spectra Comparator.

\section{E. Hög and Chr. de Vegt (Hamburg Observatory)}

\section{Chr. de Vegt reports}

A pulse counting photometer with on-line data acquisition system has been developed for simultaneous photoelectric measurements of stellar occultations in two colours. Colour splitting is provided by dichroic filters. Each channel contains a variety of filters with bandwidths between $100 \AA$ and $1000 \AA$. Bandpass regions can be selected between $3500 \AA$ and $8000 \AA$. The data acquisition system contains a Hewlett Packard 2100 computer with $12 \mathrm{~K}$ memory.

Timing of the occultation events down to $1 \mathrm{~ms}$ is achieved by a digital clock with direct computer readout. The instrumentation will be used in cooperation with the Vienna observatory at the $1.5 \mathrm{~m}$ telescope $(04.096 .001 ; 06.096 .031)$. 


\section{E. Hög reports}

A new method for automatic centering on photographic star images has been proposed $(05.031$. 035).

A design study of a multislit micrometer and a semiautomatic meridian circle has been carried out.

A scanning micrometer with on-line computer has been developed (05.034.036).

A new type of meridian circle with very small flexure of $0^{\prime \prime} .02$ has been proposed $(05.041 .043)$ and a design study has been carried out.

The photoelectric meridian circle of Bergedorf/Perth has been described (Astron. Astrophys. 1972, 19, 27).

\section{W. Iwanowska (Torún Observatory)}

At the Torún Observatory an arragnement has been developed for automatic photometry of photographic spectra by digital registering of densities and transforming them into magnitude or intensity scale by means of a computer.

\section{Kotsakis (Report for Greece)}

\section{Dept. of Astronomy, University of Ioannina}

A $63.5 \mathrm{~cm}$ reflector constracted by 'Astro-Mechanics, Inc.', U.S.A. has been installed in Ioannina in June 1971.

It is equipped with a photoelectric photometer with a photon-counting system from Central Scientific Co., Division of Cenco Instrument Corp.

Dept. of Geodetic Astronomy, University of Thessaloniki

A $76 \mathrm{~cm}$ Cassegrain reflector with asymmetric mount constructed by 'Astro-Mechanics Inc.', U.S.A., has been acquired. The focal ratio of this telescope is $F / 3$ for the primary hyperbolic mirror and $F / 13.5$ for the Cassegrain focus. All optical components are made of Cer-Vit. It has been installed at the Stefanion Astronomical Station $\left(\varphi=+37^{\circ} 45^{\prime} 15^{\prime \prime}, \lambda=-22^{\circ} 49^{\prime} 44^{\prime \prime}\right)$ and is in operation since June 1971. This telescope is equipped with the following auxiliary equipment: (1) A Johnson dual channel photoelectric photometer including one RCA 1P21 and one RCA 7102 refrigereted photomultipliers. It can be used for measurements in the $U, B, V, R, I$ colors of the international Johnson system. (2) A Meinel plane grating spectrograph with flat-field folded Schmidt camera $F / 2$ focal ratio.

\section{C.P. Kuiper (Lunar and Planetary Observatory)}

\section{Telescopes}

Catalina Observatory, nr. Tucson, Arizona, elev. 2530 meters:

42-cm Schmidt telescope, $F / 3$, curved field $7^{\circ} \times 7^{\circ}$ square, used for comet, asteroid and survey studies, in operation since mid-1972.

100 -cm photometric Cassegrain telescope, $F / 14$, on nearby peak, $2620 \mathrm{~m}$ elev., in operation since 1971.

Mt. Lemmon Infrared Observatory, elev. $2800 \mathrm{~m}, 12 \mathrm{~km}$ west of Catalina Observatory, ( $L P L$ Comm., No. 142 and 156).

152-cm photometric Cassegrain telescope, $F / 14$, operated jointly with NASA since August 1972 (was previously located at Catalina Observatory, Site II, $2580 \mathrm{~m}$ elev., operated since 1968).

$70-\mathrm{cm}$ photometric Cassegrain telescope, $F / 15$, described by H. L. Johnson in LPL Comm., No. III, 1968, previously located on Site II, Catalina Observatory; in operation since late 1972.

A $177-\mathrm{cm}$ telescope, jointly operated with other universities, is being planned. The $11 \mathrm{~m}$ dome for it is being installed in September 1972.

A $152-\mathrm{cm}$ telescope on Mt. Lemmon is owned and oprated by the Universities of Minnesota and San Diego (Calif.) since early 1971. 
Tumamoc Hill Observatory, elv. $970 \mathrm{~m}, 9 \mathrm{~km}$ from the University.

A 53-cm Cassegrain planetary telescope, $F / 30$ and $F / 100$, put into operation mid-1972.

\section{Telescopic Accessories}

An IR imaging system was devised by Low and associates, for recording planetary images at $5 \mu, 10 \mu$, and $20 \mu$. The records to date have specialized on the planet Jupiter as observed at $5 \mu$. Some thirty 2-dimensional scans are being concerted to images (isophotes), which show much structure, particularly in the equatorial zone. The initial observations were made with a Germanium bolometer, with InSb to be used hereafter. The $5 \mu$ region is of special importance because $\mathrm{NH}_{3}$ $\mathrm{CH}_{4}$, and $\mathrm{H}_{2}$ are all transparent so that observations determine the depths of the irregular cloud, patterns.

An important 500-channel spectrometer for the photo-electric range, 0.4-1.0 $\mu$, was constructed. The electronics was developed by SSR Company, Santa Monica, California, and is being applied by LPL in a dry-ice cooled mode which allows vastly longer integration times, and thus the observation of faint sources. This instrument allows digital recording of the 500 -spectral elements observed simultaneously with integration times up to about $1 \mathrm{~h}$. The spectra of 8th magnitude stars are recorded in $1 \mathrm{~min}$ with the $150-\mathrm{cm}$ telescope. One main objective is the derivation of precise albedos for planets and satellites by the method of ratio spectra.

Much time was spent in the adaptation of the original Connes interferometer, on indefinite loan, to the Coudé focus of the 229-cm Steward Observatory telescope on Kitt Peak. This instrument has led to greatly improved spectra of the four brightest planets; this program is conducted by Larson and Fink.

\section{B. M. Lasker (Cerro-Tololo Interamerican Observatory)}

At Cerro Tololo we have continued to implement the computer-operated data control and acquisition system (Publ A.S.P., 1972, 84, 207).

A second computer system is currently under construction and will be in use soon. We are also planning to install a disk operating system for the computers and a Camac data link.

\section{Latham (Astrophysical Observatory, Smithonian Institution)}

During the period 1970-1972 a 152-cm telescope was put into operation at the Observatory's Mt. Hopkins Station near Tucson, Arizona. Several new instruments have been developed for this telescope.

152-cm Tillinghast Reflector. This is an F/9.6 Cassegrain and $F / 22$ Coudé telescope with an image quality considerably better than 1 " on axis. Because a spherical primary mirror is employed, image quality degrades rather rapidly off axis. The telescope is located on Mt. Hopkins near Tucson, Arizona, on a ridge at an elevation of $7600 \mathrm{ft}$.

Echelle Spectrograph. This is a Cassegrain instrument utilizing a 30 line $\mathrm{mm}^{-1} 10 \times 20 \mathrm{~cm}$ Echelle for primary dispersion and a selection of three $10 \times 10 \mathrm{~cm}$ diffraction gratings for cross dispersion to separate orders. The spectrograph is designed for use in the wavelength range $3000-11000 \AA$ with dispersions between 1.5 and $5 \AA \mathrm{mm}^{-1}$. The camera has a focal length of $75 \mathrm{~cm}$ with an unvignetted field $40 \mathrm{~mm}$ in diameter and resolution better than $10 \mu$. The spectrograph is provided with mounts for various image tubes as well as photographic plates and films. The spectrograph has been in use since March, 1972.

Kron Electronic Camera. This electrostatically focussed electronographic camera has a $40 \mathrm{~mm}$ diameter S-11 cathode, a resolution of about 50 lines $\mathrm{mm}^{-1}$, and a detective quantum efficiency as high as $7 \%$. It has been in use since July 1971, especially in conjunction with the Echelle Spectrograph.

Image-Tube Spectrograph. This is a Cassegrain instrument utilizing various $10 \mathrm{~cm}$ diffraction gratings and a $12.5 \mathrm{~cm}$ semi-solid Schmidt camera. An ITT F4089 single stage electromagnetically focussed intensifier with a $40 \mathrm{~mm}$ diameter cathode can be used as well as photographic plates. 
Dispersions from $45 \AA \mathrm{mm}^{-1}$ to $240 \AA \mathrm{mm}^{-1}$ are available. This instrument has been in use since July 1972.

Spectrum Scanner. This is a Cassegrain instrument which utilizes a grating monochromator with automatic control of the wavelength setting. A variety of $5 \mathrm{~cm}$ diffraction gratings and photomultipliers are available to cover the wavelength range 3000 to $11000 \AA$ with band passes settable between 1 and $500 \AA$. This instrument has been in use since 1970.

Fabry-Perot Interferometer. This coude instrument is a three etalon pressure-scanned interferometer. Several sets of etalons and photomultipliers for different wavelength regions in the range 3500 to $11000 \AA$ are avilable, providing a resolution of about 500000 . The instrument has a reference beam which compensates for fluctuations in the input signal. This instrument has been in use since 1970.

Infrared photometers. Two infrared photometers for use at the Cassegrain focus are available. One employs a lead sulfice detector and a filter at $2 \cdot 4 \mu$, while the other utilizes a germanium bolometer for use with a filter in the 10- $\mu$ region. Both instruments have been in use since 1971 .

Smithsonian Astrophysical Observatory takes part in the Joint Project 'Multi-Mirror-Telescope' together with the Arizona University (see the Reports of R. L. Hilliard and A. B. Meinel).

\section{W. C. Livingston (Kitt Peak National Observatory)}

Summary of instrumental developments at KPNO during 1970-72 is given. Emphasized are major projects related directly to the observational facilities, excluding data reduction equipment (microphotometers, computers, etc.). The Quarterly Reports of KPNO are referred to as $Q R$.

\section{Planetary Science Division}

$30 \mathrm{~cm}$ Schmidt Camera (Belton. Q.R., April, 1972). Angular field $9^{\circ}$, speed $F / 2$, plate scale $316 \AA \mathrm{mm}^{-1}$, size $10.2 \times 11.4 \mathrm{~cm}$., glass, wavelength $0.36-0.58 \mathrm{~m}$.

$3.34 \mathrm{~m}$ Spectrometer (Hunten and Parkinson, Q.R., April, 1972) $\mathrm{Mars}^{\mathrm{CO}} \mathrm{O}_{2}$ bands. $\lambda / \Delta \lambda=3 \times 10^{5}$.

\section{Solar Division}

$1 \mathrm{~m}$ Path Difference Fourier Transform Spectrometer (Brault) (QR, July, 1971). Extension of the FTS technique into the visible is the aim of this project. In a single scan, taking $100^{5}$, the range $0.4>\lambda>1.4 \mu$ is covered to resolution of $5 \times 10^{5}$ and a noise of $0.1 \%$.

Infrared Spectrometer (Hall). $20 \mathrm{~m}$ f.l. for $1-15 \mu$ uses a $350 \times 450 \mathrm{~mm}$ grating blazed at $44^{\circ}$ (11.4 $\mu$ 1st order). Grating is double passed and achieves resolution of $0.01 \mathrm{~cm}^{-1}$. Grating is interferometrically positioned in angle to $\mathbf{1}^{\prime \prime}$.

Vacuum Telescope (Pierce/Livingston). Aperture $61 \mathrm{~cm}$. Focal length $30.7 \mathrm{~m}(F / 60)$. A 'Zeiss-type' coelostat directs light into a vertical vacuum tank containing a folded all-reflecting optical train. The $34 \mathrm{~cm}$ image is focused onto an in-line vertical Littrow spectrograph. The object is to provide daily magnetograms and velocity maps for synoptic purposes and for study of solar activity. Completion date: April 1973.

Optical Improvements - McMath telescope (Pierce). Intern optics have been an $203.2 \mathrm{~cm}$ quartz flat (heliostat) $152.4 \mathrm{~cm}$ quartz concave, and a $91.4 \mathrm{~cm}$ cast aluminum flat is being increased to $152 \cdot 4 \mathrm{~cm}$ to achieve less vignetting for guiding purposes. Completion date: Spring 1973.

$10 \mathrm{~cm}$ Path Difference Fourier Transform Spectrometer (Ridgway). The Idealab $10 \mathrm{~cm}$ interferometer, with a theoretical resolution of about $1 / 20 \mathrm{~cm}^{-1}$, is presently being prepared for use in the range 1 to $5 \mu$. Eventually intended for use at the $4 \mathrm{~m}$ telescope, it will be used initially at the McMath to establish wavelength standards and possibly for planetary and stellar spectroscopy.

\section{Stellar Division}

$4 m$ Telescope (Crawford, Q.R., January, 1972). 4 m, F/2.65 Ritchey-Chrétien. Building, mount, and optics are now complete and assembled. The system is being 'debugged'. Optical performance with mirror on final support: $45 \%$ of light concentrated in $0.25^{\prime \prime} ; 90 \%$ in $0.50^{\prime \prime} ; 100 \%$ in $1 \cdot 0$ " 
$4 m$ Instruments - Initial (Crawford and Hoag and Staff) Ref: January, 1972. Prime focus cameras with plateholders, film back. Ritchey-Chrétien focus $(F / 8)$ : (a) spectrograph $15.2 \mathrm{~cm}$ beam, $20 \cdot 3 \times$ $\times 25.4 \mathrm{~cm}$ gratings; (b) direct camera, film and image tube adaptation; (c) Echelle spectrograph Coudé. 3·34-m echelle spectrometer (see PSD project of Hunter and Parkinson).

Harvard Scanner (Danziger, Q.R., April, 1970) 2-channel Wampler-type scanner (low resolution dual beam scanner) (for both KPNO and CTIO).

Infra-red Photometer (Dyck and Lockwood). $1 \mu \rightarrow 20 \mu \mathrm{PbS}$ detector or Low bolometer. Utilizes secondary mirror sky chopping.

$213.4 \mathrm{~cm}$ Coude Feed (Hoag, Q.R., October, 1971). To increase use of the Coude spectrograph (which is idle $\frac{2}{3}$ of time in deference to the Cassegrain focus) Alt-Azm $152.4 \mathrm{~cm}$ flat directs light to a $91.4 \mathrm{~cm} F / 31$ off axis paraboloid replacing the $213.4 \mathrm{~cm}$ Coudé beam.

Acquisition and Centering (Kinman, Q.R., April, 1971 and July, 1971).

Uses an EBS Vidicon TV tube display continuously (but with periodic revising of picture after integration) field of view. Tests indicate reliable display to Palomar Atlas limiting mag.

Telescope Image Tube Spectrograph (Lynds) Uses thick mirror Schmidt $(F / 2)$ with full sky masking capability and photoelectric device for centering on faint objects.

Photoelectric Guider and Offset Davice (Lynds). $127 \mathrm{~cm}$ Telescope Optics Replaced (Hoag). F/13.5 Cassegrain. Cer-Vit primary and secondary; $80 \%$ of light in 1" circle.

\section{A. B. Meinel (Optical Sciences Center, The University of Arizona)}

\section{New Telescope Designs}

A method of combining multiple mirrors to constitute a single telescope system has been used as the basis for a new large telescope for the University of Arizona and the Smithsonian Astrophysical Observatory. In view of the cost of very large telescopes this design may be of interest to astronomers. (Meinel, Shannon. Optic. Ing., 1972, 11, No. 2, 33).

The Optical Siences Center is also fabricating a $2.5 \mathrm{~m}$ Bowen cassegrain system in cooperation with the Hale Astrophysical Observatories, Carnagie Institute of Washington. The primary is being polished and tested in the $10-\mathrm{m}$ beam diameter vertical testing bay of the Center. A series of tests of the mirror, in spherical figure stage, has been done with the mirror both on the hydraulic support pads of the polishing machine and the actual cell of the telescope.

\section{N. N. Michelson, V. B. Nikonov (Report for the U.S.S.R.)}

\section{Telescopes for general use}

Mounting of the 6-m telescope at the Special Astrological Observatory of the Academy of Sciences of the U.S.S.R. (SAO) near Zelechuk (Northern Caucasus) is completed. Adjustment of control system is in progress. Final figuring of the main mirror is continuing (Lutsky, 03.032.001, Kopylov, 05.032.040).

Construction of a new $2.6 \mathrm{~m}$ reflecting telescope has been completed. It was assembled at the Bjurakan Astrophysical Observatory (Armenian S.S.R.). This telescope is quite similar to the Shajn telescope of the Crimean Astrophysical Observatory, but there is not a classical Cassegrain. The prime focus with correcting systems, a three-positional Nasmith and a Coudé are provided. The control system of telescope is significantly improved.

Construction of a $1.5 \mathrm{~m}$ telescope for the Struve Astrophysical Observatory (Tyravere, Estonian S.S.R.) is nearly completed. Its optical systems are as follows: prime focus $(F: 4)$; Cassegrain $\left(F: 16 ; 2 \omega=20^{\prime}\right)$; Coudé $\left(F: 30 ; 2 \omega=6^{\prime}\right)$. Ventilation of the tube is provided. A digital computer will be used to operate the telescope and auxiliary equipment and will reduce the observations. (Demidov et al., Novaya Technika v Astronomii, 1972, No. 4, 5-7).

Some telescopes of smaller size were put in operation during the period reported: a $0.6 \mathrm{~m}$ telescope made by VEB Carl Zeiss, Jena - at the Special Astrophysical Observatory; two Sovietmade $0.7 \mathrm{~m}$ telescopes, having Newton and two Cassegrain systems $(F: 16$ and $F: 40)-$ one at the 
Gissar Astrophysical Observatory (Tadzhik S.S.R.) and the other one - at the Schemaha Astrophysical Observatory (Azerbaijan S.S.R.), equipped with a Seya-Namioka spectrometer and a semiautomatic photometer (Aslanov and Sultanov, 04.032.028). Schemaha Observatory were supplied also by $0.4 \mathrm{~m}$ astrograph produced by VEB Carl Zeiss, Jena.

At Odessa Astronomical Observatory construction of a $0.65 \mathrm{~m}$ catadioptric telescope with the optical system designed by Argunov (Astronomicheskij Vestnik, 1972, 6, No. 1, 52-61), is nearly completed.

\section{Specialized Telescopes}

Construction of two identical, fully automated Ritchey-Chrétien photoelectric $1.25 \mathrm{~m}$ telescopes is completed. Their adjustment at the factory is in progress. (Demidov and Konshin, Novaya Teknika v Astronomii, 1972, No. 4, 7-9). One of these telescopes will be supplied to the Abastumany Astrophysical Observatory and the other to the Crimean Astrophysical Observatory.

At Pulkovo Astronomical Observatory a $0.7 \mathrm{~m}$ meniscus telescope has been constructed (Maksutov, Potter). It is mounted at the Mountain Station of the Pulkovo Observatory in Nakhichevan Region (Transcaucasus).

The 'SBG' automatic camera $\left(D=0.42 \mathrm{~m}\right.$.; $\left.1: 15 ; 2 \omega=10^{\circ}\right)$, by VEB Carl Zeiss Jena, has been put in operation at the Astronomical Observatory of the Latvian University.

\section{Equipment for solar research}

At Pulkovo Observatory a digital registering system for solar spectrophotometer (Pechinskaya, Novaya Technika v Astronomii, 1970, No. 3, 88-92) has been constructed, as well as a spectrograph for observation of the solar eclipse in Mexico (1970).

The Solar Tower of the Crimean Observatory has been completely reconstructed. Its height has raised by ten meters; the mirrors are larger (the main one has $D=1.0 \mathrm{~m}$. and those of the coelostat $1 \cdot 1$. and $1 \cdot 2 \mathrm{~m}$.) and made of sital (type of Cer-Vit).

The solar equipment constructed at the Siberian Institute of Geomagnetizm (SibIZMIR) is as follows. Narrow band polarization filters for Ba II $4554 \AA$ and $\mathrm{H} \beta$ lines with pass bands of $0 \cdot 08 \AA$ (Skomorovsky, Issledovaniya po geomagnetizmu, aehronomii i fisike Solnttsa, 1970, No. 6, 107-110, Irkutsk 1971); a new type of solar magnetograph with an electro-optical deflector and a photoncounting measuring technique (Lebedev et al., Bortnik et al., 'Novaya Tekhnika v Astronomii, 1972 No. 4, 41-45); a series of solar magnetometers securing the accuracy up to $\pm 0.75 \mathrm{G}$. These magnetometers were supplied to several observatories of the U.S.S.R. The Sternberg Institute purchased from 'Opton' (FRG) a Coudé refractor with an interference filter for investigations of the active solar regions.

\section{Auxiliary and laboratory equipment}

A stellar magnetometer has been developed and put in operation at the Crimean Observatory permitting the measurement of very weak magnetic fields (Severny, 03.116.003).

A series of photoelectric scanners according to the Seya-Namioka optical system has been constructed at the Astrophysical Institute of the Kazakh Academy of Sciences (Alma-Ata) (Kharitonov, Novaya Tekhnika v Astronomii, 1970, No. 3, 39-47). They are now used at several observatories of the U.S.S.R.

The application of TV systems and Image tubes in astronomical research has been continued.

The TV method is being applied at Pulkovo Observatory to investigate the Moon in the spectral range $4600-25000 \AA$. and to study the seeing by filming tremor stellar discs with very high magnification (Kuprevich, 03.034.046; 05.031.049).

At the Crimean Observatory the TV apperatus of the $0.5 \mathrm{~m}$ Coudé telescope (Abramenko et al., 05.034.001) is used for observations of the planets and expecially of Mars (Abramenko et al., 06.097 .097 ) and also for observations of variable stars with the accuracy of $\pm 0 \mathrm{~m} 05$. It was found that visual estimation of stellar brightness from the TV photographs was a rough but very fast method of reduction giving an accuracy of $\pm 0 \mathrm{~m} 1$. (Voroshchilov and Mironova, 06.120.001). It is 
very effective, for example, when studying the periods of very faint variable stars. A TV pulsar hunter has been constructed and applied to the optical identification of pulsars (Abramenko and Prokof'eva, 04.141.206; Astr. Zirc. 1972, N0. 708, 6).

The prime focus of the $2.6 \mathrm{~m}$ Shajn telescope has been equipped with a TV system to determine the coordinates of distant space probes (class 'Luna', 'Venera', 'Mars', 'Zond'). The accuracy obtained equaled $\pm 5^{\prime \prime}$ (Anisimov et al., 05.053.001).

An image tube of cascade type is used in the prime focus of the Shajn telescope to carry out a multicolour photometry of galaxies (I. Pronik, Izv. Krim. Obs., 1971, 43, 101; 1972, 45, 162). An image tube spectrograph at the Nasmith focus of the same telescope has been in regular use since 1970 for observations of $N$ and Seyfert galaxies.

At observatory workshops several testing and laboratory equipment has been constructed. As examples we mention here the direct-intensity and digital microphotometers (SAO and SibIZMIR) (Bortnik, Osan), and a device for studying inhomogeneities of air streams inside telescope domes and in telescope tubes (SAO).

Several measuring machines of the 'Ascorecord' type (VEB Carl Zeiss, Jena) and digital computers of different types have been added to the equipment of the U.S.S.R. observatories.

Site testing

Pulkovo and Crimean Observatories organized a joint site testing expedition to Chile.

Site testing expeditions were sent by Pulkovo Observatory to Transcaucasus and Pamir.

The Sternberg Astronomical Institute organized site testing in the mountains of Samarkand Region in Central Asia. (Tertitzky, 06.032.037). For this work a double beam telescope and other equipment for site testing has been constructed (Novikov et al., 03.082.084).

\section{P. E. Nissen (Øle Romer Observatory)}

An echelle spectrophotometer has been constructed which enables us to observe the intensity of a star photoelectrically in spectral bands as narrow as $1 \AA$. The instrument is used to measure the equivalent width of a He-line in B stars and groups of weak metal lines in F, G, and $\mathrm{K}$ stars (Gustafsson, Nissen. Astron. Astroph., 1972, 19, 261).

\section{G. J. Odgers (Dominion Astrophysical Observatory)}

\section{Telescopes}

The 1.2-m telescope. Since the last report, some changes have been made to the small mirror high reflectance coudé system: (a) the turrets of prism-lens units at the last reflection point (in the coudé slit room) has been replaced with a turret of mirrors followed by a turret of lenses because the fused silica-calcium fluoride lenses cemented to the fused silica reflecting prisms had distorted and cracked; (b) an all-dielectric high reflectance coating is now used on the set of mirrors used for the blue spectral region but metal-based high reflectance coatings are still used for the ultra-violet and red regions.

An electronics room was built next to the coudé slit room to house a computer for a new drive system now under construction, and to house the electronics for detectors in the spectrograph. Periscopes were installed to permit observers to guide from the heated electronics room.

The $1.8-\mathrm{m}$ telescope. A new primary mirror, made of zero-expansion glass, is nearing completion. Fast, high reflectance spectrographs with external focal surfaces (for image tubes) are now in use; the nebular spectrographs have $F / 1.0$ cameras; $F / 1.4$ cameras are used with the stellar spectrographs which are equipped with special, Victoria-type image slicers which direct the light around the large central obstruction which is otherwise unavoidable in a fast reflection-spectrograph with an external focal surface. (ESO Conf., 1972, 275, 285; ESO Conf., 1971, 179).

The project of a Telescope Array

The project of a Telescope Array of twenty-five $1.9 \mathrm{~m}$ telescope having a common coudé focus is 
under discussion. Such an array will be equivalent to a single giant telescope of $7.6 \mathrm{~m}$. It is proposed to construct in the very near future an experimental array of two $1.5 \mathrm{~m}$ and one $1.2 \mathrm{~m}$ telescopes (Odgers and Richardson, Contr. Dominion Astrophys. Obs., 1972, No. 173).

\section{Auxiliary equipment}

In 1971 a simple high resolution spectrum scanner for use in conjunction with a 4096-address signal averager or a minicomputer was completed. The spectrum traverses the analysing slit by means of an interchangeable, rotating plane parallel plate mounted behind the coudé spectrograph slit of the $1.2 \mathrm{~m}$ telescope. Address advance pulses for the signal averager are synchronously generated by the plate rotating mechanism. A resolution of $0.3 \mu$ per address is obtained with a $1 \mathrm{~mm}$ thick plate and a plate thickness of the order of $5 \mathrm{~mm}$ or more may be used without defocussing effects becoming intolerable. The total scan is 512 addresses. The device may also be used as the scanning mechanism for a Griffin-type radial-velocity scanner.

An oscilloscope setting device for measuring spectrograms was completed in 1971. The machine employs an Abbe Comparator, modified at the Observatory to provide separate digital outputs for the scale and spiral readings, as the measuring engine. It uses a sinusoidal optical scan obtained by an oscillating mirror and a synchronized semi-sinusoidal oscilloscope sweep. The length of spectrum scanned can be varied from approximately $0.2 \mathrm{~mm}$ to $4 \mathrm{~mm}$ and with proper adjustment of the machine, the scan can be varied during the course of measuring a plate. The setting repeatability, in microns, for grain-free symmetrical lines is approximatley numerically equal to the plate scan in $\mathrm{mm}$. A wide range of spectrum dimensions can be accommodated with relative ease.

\section{G. J. Odgers (University of British Columbia)}

An integrating television system for spectroscopy has been developed by G. A. H. Walker, Auman, Buchholz, and Goldberg and has been in use since 1970. It uses a refrigerated P 850 English Electric Image Isocon as detector with on-line digitization and data acquisition by an Interdata Model 4 computer. The system has proved excellent for the observation of rapid spectrum variables. The image isocon has high sensitivity but suffers from coarse spatial resolution $(\sim 200 \mu)$ and a limited integration time $(\sim 10 \mathrm{~min})$. A description is given in the Proceedings of the Fifth Symposium on Photoelectronic Image Devices (1971) (in press). A refrigerated RCA silicon diode vidicon has been successfully substituted for the image isocon in the system and used successfully for observations in the near infrared out to a wavelength of $1 \cdot 1 \mu$.

\section{K. Osawa (Report for Japan)}

The following telescopes have been installed in Japan recently.

A $65-\mathrm{cm}$ refractor $(F=1050 \mathrm{~cm})$ newly made by Carl Zeiss was installed at the Hida Observatory $\left(\lambda=+9^{\mathrm{h}} \mathrm{g}^{\mathrm{m}} 13 \mathrm{~s} 2, \varphi=+36^{\circ} 15^{\prime} 05^{\prime \prime}, h=1290 \mathrm{~m}\right)$ of the University of Kyoto. It is equipped with modern electronic digital controls. This telescope, together with a $60 \mathrm{~cm}$ reflector which was transferred from Kyoto, will be used for photographic and visual observations of the Moon and the planets.

A Schmidt-type satellite-tracking camera was installed at the Kagoshima Space Center $\left(\lambda=+8^{\mathrm{h}} 04^{\mathrm{m}} 16 \mathrm{~s}, \varphi=+31^{\circ} 13^{\prime} 44^{\prime \prime}, h=228 \mathrm{~m}\right)$ of the University of Tokyo. The corrector plate and the main mirror are $50 \mathrm{~cm}$ and $80 \mathrm{~cm}$ in diameter respectively, and the focal length is $75 \mathrm{~cm}$. This camera is mounted on the 'four-axes' (polar, azimuth, altitude, and tracking) with automatic setting device by numerical controls. Exposure, framing, chopping and time-marking are also digitally controlled. Made by Nikon.

A $25-\mathrm{cm}$ Lyot-type coronagraph was recently built at the Coronagraph Station at Mount Norikura $\left(\lambda=+9^{\mathrm{h}} 10^{\mathrm{m}} 13 \cdot 3, \varphi=+36^{\circ} 06^{\prime} 49^{\prime \prime}, h=2876 \mathrm{~m}\right)$ of Tokyo Astronomical Observatory. This coronagraph has a coudé focus with a grating and an echelle spectrograph of dispersion $3 \sim 0.5 \AA \mathrm{mm}^{-1}$. Made by Nikon.

The following instruments for positional astronomy have also been recently installed in Japan. 
A new PZT was installed at the International Latitude Observatory of Mizusawa in 1971. Its special design enables it to automatically control the movement and the starting position of the plate carriage within the permitted limit of $\pm 0 \cdot 1 \mu$ by means of the precise pulse motor and a photoelectric device. (Iwadate, Proc. ILO of Mizusawa, 1972, No. 12).

An automatic electronic astrolabe was installed at Kanozan Observatory $\left(\lambda=+9^{\mathrm{h}} 19^{\mathrm{m}} 50 \cdot 2\right.$, $\left.\varphi=+35^{\circ} 15^{\prime} 06^{\prime \prime}\right)$ of the Geographical Survey Institute. This is a sort of pendulum astrolabe with an electronic transit detector (Tsubocava, Hokugo).

\section{F. Roddier (Department d'Astrophysique de l'UERMST, Nice)}

Le réfracteur coudé (diametre $40 \mathrm{~cm}$ ) de l'Observatoire de Nice, abandonné depuis 35 ans, a été remis en état et adapté dans le but d'y effectuer des observations solaires (miroirs plans en Cervit, foyer refroidi). Les premiers essais sur le soleil sont prévus pour la fin de 1972. L'entraînement sera refait en 1973.

Un dispositif a resonance optique de sodium a été réalisé pour l'étude photoélectrique des vitesses radiales a la surface du soleil. Un filtre optique permettant d'isoler une frêquence spatiale déterminée a été mis au point. Il permet d'étudier la structure spatiale des oscillatoires de la photosphère. Les signaux, enregistrés sur bandes magnétiques, peuvent être analysés en temps réel sur un petit ordinateur (analyse de Fourier temporelle).

Par ailleurs, des méthodes identiques (filtrage optique suivi d'une analyse de Fourier temporelle) ont été appliquées a l'étude des ombres volantes (scintillation stellaire). On a pu mettre ainsi en évidence plusieurs couches atmosphériques turbulentess et évaluer leur altitude et leur contribution respectives à la scintillation. Cette technique pourrait s'avérer intéressante pour la recherche des sites d'observatoires astronomiques.

\section{J. Rösch (Observatoire du Pic du Midi et de Toulouse)}

Le projet en cours le plus important est celui du telescope de $2 \mathrm{~m}$ de diametre utile, qui vise à obtenir la plus haute réduction engulaire possible et portera le nom de 'Télescope Bernard Lyot'. Les combinaisons optiques prevues sont: - un 'primaire replie' (type Strand) donnant une longueur focale de $10 \mathrm{~m}$; - un Cassegrain $F / 25$ (avec possibilité ultérieure d'un rapport $F / 15$ ); - un foyer coudé, ultérieurement. L'emplacement a été choisi après des études en soufflerie sur une maquette de la montagne et des bâtiments. La tour, de $14 \mathrm{~m}$ de diametre et $28 \mathrm{~m}$ de haut, est achevée, ainsi que le pilier, du type 'table a quatre pieds'. La monture, du type 'fer a cheval' et la coupole (entièrement fermée) seront misses en place au cours de l'été 1974, et les essais sont attendus pour la fin de 1975.

Depuis le dernier Rapport de la Commission 9, l'Equatorial installé par Benjamin Baillaud en 1907, qui est resté longtemps le seul instrument important de l'Observatoire, a été démonté pour renovation et remplacé par une table equatoriale du type 'toupie', dont le cercle lisse de $3.2 \mathrm{~m}$ de diamètre, repose sur seux galets, munis d'embrayages, l'un donnant les mouvements rapides et l'autre le mouvement diurne et les mounvements lents. Le second galet est entrainé par un moteur pas à pas alimenté par un synthétiseur de frequence. L'ensemble s'est avéré d'une très grande souplesse d'emploi. La table équatoriale porte maintenant le Coronographe de $20 \mathrm{~cm}$ de Lyot (avec spectrographe), le polarimètre $\mathrm{K}$, et un Coronographe de $26 \mathrm{~cm}$ pour lequel Ratier construit un polarimetre a protubérances.

On signalera comme autre nouveauté la realisation par Texereau d'un objectif de $50 \mathrm{~cm}$ et $6.5 \mathrm{~m}$ de longueur focale destiné à remplacer, a la fin de 1972, l'objectif ancien de $38 \mathrm{~cm}$ qui a fourni les premières observations de planètes de Lyot, et par la suite tous les résultats obtenus sur la granulation et les taches solaires.

\section{F. Ruffener (Observatoire de Geneve)}

An automatic guiding system has been built and is now in operation at our $1-\mathrm{m}$ telescope located 
in Haute-Provence Observatory. It is an auxiliary $30 \mathrm{~cm}$ telescope with an ITT FW 129 image dissector having a square diaphragm.

A dual beam photometer for differential and quasi-simultaneous seven-color observations is coming in operation. It will open new fields for the $U B V B_{1} B_{2} V_{1} G$ system (variable and faint stars) and allow the use of imperfect photometric skies. A 14 channel real time treatment for the photon counter is operated by a mini-computer. (Burnet and Rufener).

A micro-densitometer has been built and is now being tested. This instrument has a special design to permit a semiautomatic evaluation of stellar magnitudes on electronographic plates obtained with a Lallemand electronic camera through filters of the Geneva photometric system. (Pilloud and Goy).

A Griffin-type spectrophotometer for measuring radial velocities at the Cassegrain focus of a 1-m telescope is under construction. The project is cooperative effort of Marseille and Geneva Observatories. (Baranne, Mayor, and Poncet).

\section{J. Sahade (Report for Argentina)}

\section{Argentine Naval Observatory.}

In 1970 a PZT station at Punta Indio ( $\left.\varphi=-34^{\circ} 20^{\prime} 40^{\prime \prime} 65 ; \lambda=3^{\mathrm{h}} 49^{\mathrm{m}} 08.630 \mathrm{~W}\right)$, operated jointly with the La Plata Observatory, started regular operations. The PZT was provided by the U.S. Naval Observatory under an agreement with the University of La Plata and the Argentine Naval Hydrographic Service.

Through an agreement between the University of Besanson, France, and the Argentine Naval Observatory and La Plata Observatory, a Danjon impersonal astrolabe in being operated at Punta Indio since August, 1971.

Institute of Astronomy and Space Physics.

It is planned to build, during 1973, a portable two-channel high speed photoelectric photometer with the output on magnetic tape.

\section{G. Schmahl (Universitäts-Sternwarte Göttingen)}

In the optical laboratory of the Göttingen Observatory the further development of holographic gratings led to blazed plane reflectance gratings up to a width of $200 \mathrm{~mm}$ and to concave gratings up to a diameter of $350 \mathrm{~mm}$. The efficiency, especially for gratings with high line densities $\left(\geqslant 1200 \mathrm{lmm}^{-1}\right)$ could be improved (G. Schmahl and D. Rudolph, ESO Conf., 1972, 209).

\section{A. Schroeder; personal report (Beliot College, Wisconsin)}

Most of my work has been in the area of echelle spectrographs $(04.034 .082 ; 06.034 .085)$.

I also designed an echelle instrument for the use of the 1.52-m telescope at the Mt. Hopkins Observatory of the Smithsonian Astrophysical Observatory. This instrument has been in use since March 1972, and has been used primarily with a Kron electronographic camera. With this detector the spectrum of a 5 th-mag. star can be recorded in $15 \mathrm{~min}$ with a spectral revolution of $0 \cdot 2-0 \cdot 3 \AA$ in the blue.

Another echelle spectrograph of my design has been used by O'Dell and Gull of Yerkes Observatory. This instrument employs a Schmidt camera with electrostatic image tube, and has been mounted in a jet airplane for making observations in the infra-red of planets and nebulae.

Work is now proceeding at the Kitt Peak National Observatory on an echelle spectrograph for the 4.0-m KPNO telescope. This work is under the direction of Gull, following my preliminary design, and is intended for use with a wide variety of detectors, including Kron-camera and magneticallyfocussed image tubes. Detailed engineering design has just begun on this instrument.

\section{H. Seddon (Royal Observatory Edinburgh)}

The automatic luminosity and XY coordinate measuring machine GALAXY, (Walker, Proc. 
Roy. obs. Edinb., 1971, 8, 103), (Pratt, Proc. Roy. Obs. Edinb., 1971, 8, 109) has measured to date (September, 1972) $5 \frac{1}{2}$ million star images on more than 500 plates for thirty different establishments, nine of these being from the U.K. In addition to this use, the high accuracy of positional measures (better than $1 \mu \mathrm{m}$ ) has been used for measuring geodetic satellite trail photographs and for astrometry (Dodd, Astron. J.,1972, 77, 36). It is shown there, by comparison with conventional measures, to be free from systematic errors over a range of at least eight magnitudes.

Development of the GALAXY machine continues, with Mark 2 due to be commissioned in 1973. This machine will measure a $35 \mathrm{~cm}$ square plate in a day, recording positions to $4 \mu \mathrm{m}$, brightness to 0.1 mag. and image shape data on magnetic tape. It will also have an elliptical scan mode to measure galaxies as well as stars to $0.5 \mu \mathrm{m}$ and $0.02 \mathrm{mag}$. a digital surface photometry mode; and an objective prism spectra scan.

An automatic star follower has been designed (Adam, Proc. Roy. Obs. Edinb., 1971, 8, 43) which is now produced commercially under license. Its very high guiding accuracy of $2 \mu \mathrm{m}$ at focus permits the recording of better Schmidt star images than can be obtained by hand-guiding.

Exposure control of moderate dispersion spectra on the $90 \mathrm{~cm}$ telescope has been modified to a stepping mode, the spectrum being each element exposure. This procedure produces properly exposed spectra of width proportional to the total exposure, resulting in less wastage due to interruption.

A scanning spectropolarimeter was designed and built, being used at prime focus of the Cambridge $90 \mathrm{~cm}$ telescope for measurement of detailed polarisation profiles (Wolstencroft and Nandy, 06.131.023).

A new 2 metre Michelson stellar interferometer is nearing completion at the Observatory's outstation at Monte Porzio, Italy. Mounted altazimuthally, it will be used for a survey of close binaries.

Much instrumentation work has been carried out in connection with national facilities. An initial systems analysis was carried out for the Anglo-Australian telescope. An investigation has been made of the feasibility of eliminating field rotation in altazimuth systems by the use of two of the autoguiders just referred to. The results were very encouraging. Instruments have been produced for site testing in the Northern Hemisphere, these being a set of three Polaris trail telescopes on the Harlan and Walker design, three night sky photometers and various meteorological instruments. A drive and control system for the $150 \mathrm{~cm}$ infrared flux collector on Tenerife was designed and built. The drive provides the standard functions and also fast scanning over a wide range of amplitudes and speeds for search purposes.

Infrared work continues to expand. The Fourier spectrometer has been used with cooled detectors to $5 \mu \mathrm{m}$, and design of a four-part configuration is under way to improve signal to noise both with balanced interferograms and sky background subtraction at longer wavelengths. Equipment for broad and narrow band photometry has been acquired and built for wavelengths to $25 \mu \mathrm{m}$, incorporating Low bolometers.

\section{J. Stock (Instituto Venozolano de Astronomia)}

The new Venezuelan Observatory will be built on a site which is called 'Loma de las Mucuras', at an altitude of $3610 \mathrm{~m}$, located about $50 \mathrm{~km} \mathrm{NE}$ of the city of Merida in the Venezuelan Andes Mountains. The telescopes to be installed are:

A Schmidt telescope of $100 \mathrm{~cm}$ aperture (primary $150 \mathrm{~cm}$ ), $F / 3$, equipped with an objective prism. Corrector plate as well as the prism are made of UV - transparent material (UBK7).

A Double-astrograph, one objective for the blue, the other for the visual spectral region, both of $65 \mathrm{~cm}$ aperture.

A long refractor of $65 \mathrm{~cm}$ aperture.

A reflector of $100 \mathrm{~cm}$ aperture.

Concerning astronomical techniques, we have developped a method which permits the derivation of radial velocities from pairs of objective prism plates obtained with Schmidt telescopes. The first report on the method should appear in the proceedings of IAU Symp. $\mathbf{5 0 .}$

We expect to put the Schmidt telescope into operation during 1973, with the other three telescopes following in 1974. 


\author{
R. G. Tull and G. de Vaucouleurs (McDonald Observatory, University of Texas)
}

\title{
R. G. Tull reports
}

\section{Telescopes}

The 2.7-m telescope was completed and put into operation in March, 1969. The telescope is operated at the Ritchey-Chrétien $F / 9$ focus, at $F / 18$ Cassegrain and at $F / 33$ coude, the changes being made by removable cages. It is planned to remount the $F / 9$ and $F / 33$ secondaries in the near future in a new configuration to allow rapid interchange by rotating the support spider assembly in order to rapidly change between cassegrain and coudé operation for the lunar laser ranging program.

A $76 \mathrm{~cm}$ Cassegrain telescope built by Boller and Chivens was placed in operation in 1971.

The classical telescope drive system usually employs a large worm gear on the polar axis. The original wormgear drives for the $2.7-\mathrm{m}$ telescope, in both right ascension and declination, were damaged during installation and have led to severe limitations on telescope operation. In October 1972 the drive systems are being replaced with preloaded spur gear drives with closed-loop digital control (Thompson and Floyd, Internat. Symp. on Gearing and Transmissions, San Francisco, Calif., Oct. 1972).

\section{Auxiliary instrumentation}

A high-dispersion spectrograph was installed at the coudé focus of the $2 \cdot 7-\mathrm{m}$ telescope and went into operation in 1969 . The collimated beam diameter is $24 \mathrm{~cm}$. There are 3 plane gratings, $20 \times 30 \mathrm{~cm}$ in size, working in the first to third spectral orders. The two cameras (classical Schmidts), with mirrors of $1-\mathrm{m}$ and $1.5 \mathrm{-m}$ diam and focal lengths of $1.8 \mathrm{-m}$ and $4.3 \mathrm{-m}$ respectively, yield photographic dispersions ranging from 1 to $18 \AA \mathrm{mm}^{-1}$. The spectrograph operates with dispersion in the horizontal plane and occupies much of the 3rd and 4th floors of the observatory building; it is supported on the telescope piers and fully isolated from the building. Auxiliary equipment includes a reflective image rotator, a stepped spectral calibration source, exposure meter, Richardson-type image slicers, guiding optics, and field viewing optics, all mounted on an optical bench in the slit room; and means to select either of two high-reflectivity mirrors at each of three locations: at the numbers 4 and 5 flats, and at the collimator (Sky and Tel., 1969, 38, 156).

A high-dispersion single-channel rapid-scanning spectrophotometer has been developed, using the coudé spectrograph of the $2.7-\mathrm{m}$ telescope in Littrow. Limiting spectral resolution up to 400000 has been achieved, using a $20 \times 40 \mathrm{~cm}$ Bausch and Lomb Echelle with 79 grooves $\mathrm{mm}^{-1}$ in double pass, in 36th order. Absorption lines of $\mathrm{H}_{2} \mathrm{O}$, doppler-shifted, have been detected in the atmosphere of Mars down to a limit of $0.5 \mathrm{~mA}$ equivalent width; the first observations of molecular oxygen on Mars were achieved with this equipment.

The Jet Propulsion Laboratory, Calif. Inst. of Technology, has installed a Fourier transform interferometer spectrometer, designed by Reinhard Beer and closely following the design of Pierre and Janinne Connes, at the coudé focus of the 2.7-m telescope (Rev. Sci. Instr., 1971, 42, 1393).

A Pepsios pressure-scanned Fabry-Perot spectrometer has been installed at the coude focus of the 2.7-m telescope by The University of Chicago.

The Manned Spaceflight Center has installed a Block Interferometer at the coudé focus. These various instruments are selected by rotating a mirror turret at the Number 5 position.

\section{Computer control and processing in astronomy}

An IBM 1800 computer has been installed in the $2 \cdot 7-\mathrm{m}$ telescope building; several mini-computers (Data General Corp. NOVA and NOVA-1200) are used at various telescopes.

The 1800 is used as (a) a time-sharing central information and computing facility for advisory aid to the observers; (b) a limited-purpose telescope control computer for offsetting the $2 \cdot 7-\mathrm{m}$ telescope; (c) a central data storage facility; (d) a data reduction facility. All of these functions operate in a priority-interrupt time sharing mode.

The mini-computers are used as dedicated instrumentation control and data collection systems. 
Operation of the coudé rapid-scanning spectrophotometer is under the control of a NOVA 1200. The Cassegrain spectrophotometer is operated by a second NOVA (Publ. A.S.P., 1972, 84, 203). Photometry of rapidly-varying events (stellar flares, occulations, eclipsing binaries, cataclysmic variables, optical pulsars) is carried out by NOVA computer control of broadband filter photometers. Area-scanning photometers, used rimarily for photometry of stars or satellites against a bright background, are in regular operation with NOVA computer control (Astron. J. 1972, 77, 41).

A computer-operated microdensitometer came into operation on the Austin campus of the University of Texas in 1971. Photographic plate areas up to $16 \times 32 \mathrm{~cm}$ are scanned in steps down to $1 \mu$. This is a double-beam null balance machine; the neutral density wedge in the reference beam is driven toward balance by the NOVA computer in density steps of $0 \cdot 001$. The small residual balance error is computed from the intensity ratio of the two beams and is applied as a correction to the wedge position. The mean of several such determinations of corrected wedge position constitutes a plate density determination with output on IBM-compatible magnetic tape.

\section{Data processing techniques}

Photoelectric spectrophotometric data have in the past been difficult and time-consuming to process. The new techniques involving photon counting, computer control, and direct entry of the digital data into the system of computers at McDonald Observatory has removed the difficulty of encoding the data into computer-compatible format.

Processing of, e.g., the coudé scanner data now goes through a multi-step process: (1) Photon counts from rapid repetitive scans are co-added into the memory of a NOVA 1200 computer. (2) At the end of an observation these data are transferred to the IBM 1800 computer and stored on a disk file. Transfer time averages about $5 \mathrm{~s}$. (3) On command (usually the following day) the data files are brought into core memory of the 1800 , punched onto IBM cards, and plotted. (4) Additional data processing may be carried out on the 1800 ; in general, however, (5) the card files are transported to the CDC 6600/6400 computers at the University of Texas in Austin for further processing.

Important new advances in data processing have been made practicable by these advances in data handling at the observatory; in particular, the new techniques of digital filtering applied to the Fourier transform of the data set have been implemented (unpublished dissertation, Donald $\mathrm{C}$. Wells III, University of Texas, 1972) (Astron. and Astrophys., 13, (1971), 169).

\section{Detectors}

Photomultipliers. The new III-V 'negative electron affinity' cathodes have been incorporated in a new series of RCA photomultipliers (Type C-31034). We have obtained several and have one in regular operation with the coudé scanner. These have a flat spectral response from about $300 \mathrm{~mm}$ to $870 \mathrm{~mm}$, and acceptably low dark count. The quantum efficiency in the red is an order of magnitude greater than in the S-20 and S-25 cathodes; however, manufacturing difficulties have, hopefully temporarily, stopped further deliveries from RCA.

Multi-channel detectors. A 256-channel 'self-scanning' arry of silicon diodes, mounted on an integrated circuit chip, has been obtained; the characteristics of this device are being determined for possible use in spectrophotometry.

\section{G. de Vaucouleurs reports}

\section{Instrumental developments}

Several important instrumental developments took place or were completed during the report period. A fully automated, computer-controlled spectrophotometer was placed in regular operation at the Cassegrain focus of the 82-in reflector. We used it for radial velocity and velocity dispersion studies in several important galaxies.

An improved, 2-stage fiber optics image converter (VARO S25VR) was placed in regular operation, thereby reducing exposure times for spectroscopy and interferometry from several hours to a few minutes. 
Two (interchangeable) compact, direct-vision grating-prism combinations were acquired to construct a convenient low-dispersion nebular spectrograph $\left(180-360 \AA \mathrm{mm}^{-1}\right)$ for work in the visible and infrared $(\lambda \lambda 4500-8500)$ in conjunction with the image tube.

A new Fabry-Perot interferometer specially designed for $\mathrm{H} \alpha$ work on galaxies (order $p=1060$ ) was installed and used in conjunction with the image tube to begin high resolution studies of rotation and internal motions in galaxies.

A projection measuring machine specially designed for rapid measurement of interferograms was designed and tested.

\section{P. Treanor S. J. (Specola Vaticana)}

An image tube spectrograph, using a magnetically focussed 2-stage RCA image intensifier and combining efficiency with the compactness and weight restrictions of a $60 \mathrm{~cm}$ reflector has been constructed (Treanor, Ric. Astron. 1970 8, No. 4.; 04.034.066).

The geometry of spectra formed by crossed prisms has been considered (Junkes, 06.031.030.; Ric. Spettrose., 3, No. 4, in press).

It was shown that the use of a Schott RG645 filter with 103aE plates and high objective prism dispersion yields a narrower band pass and a higher emission continuum ratio than other filter-prismemulsion combinations hitherto in general use. This results in an improved signal/noise ratio of the emission feature in objective prism spectra and consequently to a fainter detection limit for $\mathrm{H} \alpha$ objects (McCarthy and Treanor, 03.034.053).

Refinements of the ring polarimeter technique developed by Treanor, which now allow the rapid determination of the amount as well as the direction of stellar polarisation of faint stars, have been considered (Treanor, IAU Symp. 54, 1972, in press).

A table, intended to facilitate calculations of the polarisation of light that has passed through two polarising agents has been published. It is applicable to polarising interstellar clouds and to instrumental polarisation effects (Bertiau and Coyne, 05.061.033).

Treanor suggested a low relating the artificially produced zenith intensity of the night sky to the proximity of cities of known population and degree of industrial development. The practical validity of this low has been established and applied to determine the night sky artificial illumination over Italy and the Italian islands, revealing areas of low illumination in southern Italy and Sardinia. This work is related to the site-testing projects of the Italian National Observatory, the Vatican Observatory and the British Northern Hemisphere Large Telescope. (Bertiau and Treanor 1972, in press).

A portable photometer for night sky brightness measurements, for use in observatory site-prospecting, has been developed (Treanor and Salpeter, Observatory, 1972, 92, 96).

\section{W. F. Van Altena (Yerkes Observatory)}

An automatic guiding camera has been designed by Van Altena for the $1 \mathrm{~m}$ refractor and built in the Observatory workshops. The guider derives its error signal from a knife-edge spinning at 1800 rpm which is located in the hollow rotor of the synchronous motor. The automatic guider was placed into operation in January 1971 and has substantially increased the average image quality and allowed work on nights when manual guiding would have been nearly impossible.

A photoelectric parallax scanner has been designed by van Altena for the measurement of trigonometric stellar parallaxes at the telescope. The concept of the instrument is similar to Griffin's photoelectric radial velocity spectrometer except that a high contrast photographic positive of the parallax field is used as a mask and the modulated light from the parallax star and the reference stars is viewed separately by two photomultipliers, whose output is recorded on a two-pen chart recorder. Measurement of the separation of the reference and parallax star transmission peaks on the chart yields a direct measurement of the image displacement due to parallax and proper motion. With the measurement of plates eliminated, the only reductions required will be that for parallax and proper 
motion. Preliminary tests of the prototype instrument are continuing on the $1 \mathrm{~m}$ refractor with encouraging results.

A vacuum platten plate holder has been designed by Thronson, Jr. and van Altena for use with the $104 \mathrm{~cm}$ reflector. The curvature of the platten is designed to match the curvature of the focal plane and extends the useable field of the $104 \mathrm{~cm}$ reflector to 1.25 degrees without corrector optics.

A step-wedge sensitometer designed at KPNO for the $4 \mathrm{~m}$ telescope has been constructed in the Observatory shops for calibration of photographic plates over a greater intensity range than was possible with the linear wedge sensitometer.

\section{H. Van de Stadt (The Astronomical Institute Utrecht)}

The solar group made a low-noise digital photoelectric scanner to be used in the solar spectrograph. A fully automatic-controlled digital microphotometer was specially constructed for our observatory. The high positional accuracy (better than $1 \mu$ ) the automatic focus control and many other applied techniques give this instrument unprecedented high quality. Instruments for high resolution heterodyne detection techniques with lasers were accurately calibrated and used for solar measurements. Development of infrared heterodyne detectors is well underway and they will soon become operational.

\section{A. A. E. Wallenquist (Report for Sweden)}

\section{The Lund Observatory (Lund)}

The micro-photometer of the Lund Observatory has been rebuilt and equipped with computer control. An HP 2116B with $16 \mathrm{~K}$ memory can order movement of plate carriage as well as receive and reduce measurements of plate transparancy. Output units are a terminal, a tape punch and a digital plotter. It has been found that the BASIC language provides most flexibility for the measurement procedures. Slit spectra as well as objective prism spectra are measured automatically with the equipment.

The photometric equipment of the $61 \mathrm{~cm}$ Cassegrain-Nasmyth $F / 15$ telescope (Hansson and Schalen, Ark. f. Astr., 1968, 5, 197=Lund Obs. Medd. Ser. 1, No. 236) at the Javan Station has been supplemented with filters and photo-cells for broad and narrow-band photometry in various regions. A spectrograph has been ordered for the telescope.

\section{Stockholm Observatory (Saltsjöbaden)}

New filter technique. Kerstin Fredga and Högbom have developed the theory of the Solc-type birefringent filter. They have shown how only by rotating the individual crystal plates in the filter the width of the transmission profile can be varied and how at the same time the detailed shape of the profile can be controlled (sidelobes, square bands, double peaks). By the same means the transmission band can also be tuned in wavelength. (Kerstin Fredga and Hogbom. IAU Symp. 41, 'New Techniques in Space Astronomy' (ed. by Labuhn and Lüst), p. 372, 1971; Kerstin, Fredga and Högbom, Solar Physics, 1971, 20, 204.

New instruments at the Stockholm Observatory, Saltsjobaden, and at the observing station at Capri, Italy (Stazione Astrofisica Svedese).

The $1 \mathrm{~m}$ reflector at Saltsjobaden has been equipped with the following three instruments to be used at the Cassegrain focus:

(1) Grating spectrograph from Boller and Chivens, California, with $90 \mathrm{~mm}$ diameter collimator. Its Bowen Schmidt Cassegrain in camera can be used with an image intensifier.

(2) Infrared photometer used at wavelengths $1.25,1 \cdot 26,2.2$, and $3.7 \mu$.

(3) Scanning low-dispersion spectrometer with cooled pindiode for $\lambda 0 \cdot 4-1 \cdot 0 \mu$. - The instruments 2 and 3 have been constructed by Olofsson and Nordh. A multichannel integrator and tape punch are used for data recording. 
The recording micro-photometer (for spectrograms) has been improved and equipped with digital output on magnetic tape.

A $60 \mathrm{~cm}$ reffecting telescope for stellar photometry has been installed (1972) at the observing station at Capri. It was built in Copenhagen for the Swedish Royal Academy of Sciences. A new photoelectric photometer for this instrument is under construction at the Stockholm Observatory.

Ebert-Fastie spectrograph with Bausch-Lomb grating $12001 \mathrm{~mm}^{-1}$ for solar work.

The Uppsala Observatory (Uppsala) and the Kvistaberg Station (Bro).

A new photometric telescope of Cassegrain type $F / 9$ and $41 \mathrm{~cm}$ primary mirror has been mounted at the Kvistaberg Station. It is equipped with a photoelectric photometer constructed at the Uppsala Observatory. It is used for broad and narrow-band photometry. It has a peltierelement-cooled photomultiplier EMI $6256 \mathrm{SA}$. The output current from the photomultiplier is after current-voltage conversion amplified and connected to a voltage-frequence converter. The pulse-train is via the integrator connected to a pulsecounter and the number of pulses during the integration time is visible on a digital display in the control desk. In the control desk is also located an analog paperrecorder.

\section{The Uppsala Observatory (Uppsala)}

A new blink-comparator has been built at the Observatory. The instrument consists of a movable plate-table with two plateholders, interchangeable objectives, prisms, mirrors, ground glass-screen a blinking device and two lamphouses. The blinking frequency can be adjusted between 1 to $7 \mathrm{~Hz}$. The two lamps can be dimmed individually by means of thyristor-regulators. In changing the objectives it is possible to work with 30 or 50 times magnifications on the ground glass-screen.

\section{B. Wellgate (Royal Greenwich Observatory)}

The Isaac Newton Telescope has been fitted with a new drive for both Right Ascension and Declination. It makes use of stepping motors and has a programmable rate generator (crystalcontrolled) which allows fast and slow motion, offsetting, trailing, scanning, etc., with a resolution of a fraction of one arc second. Provision has been made for control by a computer by a later date.

This drive works satisfactorily and is a distinct improvement on the previous one.

A Mark II version of the Unit Spectrograph, using a Spectracon intensifier tube is now operational on the Isaac Newton Telescope.

\section{B. E. Westerlund (European Southern Observatory)}

In addition to the telescopes listed by Prof. Fehrenbach in IAU Transactions XIVA. ESO has now also on La Silla a $50-\mathrm{cm} F / 15$ telescope for photoelectric observations. Our Schmidt telescope (free aperture $1 \mathrm{~m}$, mirror $1.6 \mathrm{~m}$ diameter, and focal length $3 \mathrm{~m}$ ) is mounted and almost ready for regular use. We have an objective prism of UBK 7 glass giving a dispersion of about $580 \AA \mathrm{mm}^{-1}$ at the $\mathrm{H} \gamma$ line.

The Zeiss Camera of the $1.5 \mathrm{~m}$ Telescope was modified for Image Tube work. An Image Tube ITT 4708 is being used.

The Fabry-Perot Interferometer. This instrument will provide about $0 \cdot 1 \AA \AA$ resolution of emission lines in two spectral ranges $3500-4200 \AA$ and $6200-6800 \AA$.

A digital spectrum scanner was built for the Nasmith focus of the $1 \mathrm{~m}$ Telescope (ESO Conf., 1972, 165).

The $3.66 \mathrm{~m}$ Telescope is under construction.

\section{O. R. White (High Altitude Observatory)}

On 1 July 1972 the High Altitude Observatory ceased operation of its Climax Station after $30 \mathrm{yr}$ of continuous service in observational solar astronomy. Observational work will continue under better conditions and in the form of new HAO projects at Sacramento Peak Observatory, at our 
Mauna Loa site in Hawaii, on instrumented aircraft operated by the National Center for Atmospheric Research, and on the Skylab (formerly ATM) and OSO-1 spacecraft.

Application of Fourier Techniques to Solar Data. In collaboration with Brault (Kitt Peak National Observatory), White applied Fourier Transform to noisy (i.e., real data). The development of the Feast Fourier Transform algorithm and the application of optimum filter technique now permit a 'best' numerical solution to the correction problem for real data. As a result we can now specify constraints on the data collection process to insure that the Fourier representation of the data is accurate enough for good recovery of the true profile. This method also permits construction the optimum numerical filter from the data (05.021.008).

A Computer-Controlled Infrared Eclipse Telescope. An F/8, chopped, dual beam, gyroscopically pointed telescope has been constructed for use in obtaining infrared $(7-13 \mu)$ observations of the spectrum of the thermal emission of the solar corona. The instrument employs a scanning Michelson interferometer with germanium beam splitter and a germanium bolometer operated at $2 \mathrm{~K}$. The resulting interferogramms are stored on magnetic tape. A small general purpose digital computer is used for experimental control and data processing. A fourier transformed spectrum may be generated on operator request (Lee, MacQueen and Mankin, 04.032.040).

The High Altitude Observatory Stokes Polarimeter. The successful use of the HAO longitudinal magnetograph at Climax to study prominence magnetic fields (see Tandberg-Hanassen 1970 for a review of the literature), prompted Tandberg-Hanssen to plan a full Stokes polarimeter in the hope of investigating the vector field in prominences. The design concepts of the polarimeter are mainly due to Beckers and Lee, while Baur, Curtis, Hull and Rush have been responsible for building the instrument. One of the unique aspects of this instrument is that it is designed to operate at low light levels so that the Stokes spectrum of prominences and even the corona can be measured, and an elaborate calibrative scheme has been devised by Baur.

The polarimeter employs two electro-optic light modulators (KD P cells) driven at different frequencies, followed by a quarter ware plate and a polaroid. The two beams from the polaroid are fed to two photocells, and by taking the sum and difference signals from the cells, the four Stokes parameters are obtained, using three lock-in amplifiers.

The instrument was tested successfully on the big spar of the Sacramento Peak Observatory coronagraph in February 1972. After some modification and being brought under computer control, it is hoped that it will be operational during the winter of 1972-73 (Tandverg Hausen, 04.073.059).

\title{
V. B. NIKONOV \\ President of Commission
}

\author{
JOINT WORKING GROUP OF COMMISSIONS 9 AND 46 FOR \\ EXCHANGE OF EQUIPMENT
}

A Circular Letter was sent to the directors of all astronomical institutes and observatories asking if there is any possibility for loaning some types of astronomical equipment.

Many answers were received up to November 1972, all of them negative. Some observatories have already loaned their excess equipment. Another, recently organized, does not have such equipment.

N. N. MIHELSON

Chairman of the Working Group

GROUPE DE TRAVAIL SUR L'EMPLOI EN ASTRONOMIE

DES RÉCEPTEURS PHOTOÉLECTRIQUES D'IMAGES

\section{Introduction}

L'emploi de ces récepteurs a continué à se développer au cours des deux dernières années. Cette activité est confirmée par l'organisation de plusieurs réunions spécialisées et par la parution d'articles de synthèse, notamment: 